\title{
Considerations and costs of disclosing study findings to research participants
}

\section{Conrad V. Fernandez, Chris Skedgel, Charles Weijer}

T The disclosure of study findings to participants in research reflects the moral obligation of researchers, founded in the ethical principle of respect for human dignity, to avoid treating human participants as a means to an end. Human dignity is respected through proper procedures of obtaining informed consent, and an offer to provide research results to participants extends this respect. Unfortunately, researchers adhere inconsistently to this responsibility, ${ }^{1,2}$ and little guidance is provided in regulatory policies ${ }^{3,4}$ even though a desire for such information has been expressed by research participants. ${ }^{5}$ Recently there has been a compelling call to offer research results to participants in clinical trials; ${ }^{6}$ we have extended this argument to include all participants in human research. ${ }^{7}$

Funding agencies should support the allocation and use of research monies in an ethical manner and, thus, should support the appropriate disclosure of results to individual participants and to communities. ${ }^{8}$ However, the disclosure of results has economic implications for researchers in planning their budgets and for funding agencies in determining an appropriate level and duration of funding. In this article, we briefly review the rationale for offering to disclose research results, focus on specific factors that influence the cost of such a practice and suggest an approach for researchers and funding agencies to consider when developing or assessing research grant applications.

\section{The rationale for disclosure}

The offer and receipt of research results has many potential benefits for participants and may have a direct impact on their quality of life. For example, research has shown that women who received mantle radiation for Hodgkin's disease as teenagers are at high risk for secondary breast cancer; 9 providing research results to these women may benefit them directly. Participants also benefit from the affirmation of the key role they play in the conduct of research. Disclosure of results may also benefit research as a whole by demonstrating its tangible benefits to the public and by engaging public enthusiasm and support for the principle of research.

The receipt of results is not without potential for harm and thus requires informed consent and careful design of disclosure programs. ${ }^{7}$ The possible harms encompass immediate effects, for example distress at learning that one has participated in an inferior arm of a clinical trial, and longer-term harms, including a potential impact on the ability to obtain insurance by those with an anticipated high rate of late effects.

Research participants have indicated that results should be shared in a timely manner. ${ }^{10,11}$ The need for peer review before disclosure to study participants has very significant implications for researchers and funding agencies. ${ }^{7}$ The resulting increase in the time from the end of data collection to peer review and subsequent publication will require substantially longer periods of research funding than are usually allowed for. ${ }^{12,13}$ Thus, the moral imperative to offer to return research results will require changes in funding practice to allow for this time frame.

It should be emphasized that no participant is obligated to receive results that he or she does not wish. Participants must be informed of the potential harms and benefits of receiving results. ${ }^{14-16} \mathrm{We}$ argue solely for the universal offering of results with appropriate support.

\section{Assessing the cost of disclosure}

Factors that affect the complexity of returning research results, and thus costs, fall into 3 broad categories: the risks associated with nontherapeutic and therapeutic procedures of the study; $;^{17}$ the short- and long-term consequences of disclosure, including harms; and the logistics of the study, including its duration and the number and geographic location of the participants. Assessment of these factors can then be used to determine the requirements for returning results (Table 1), following a template of basic elements (Box 1).

\section{Study risk}

Almost all studies involving interventions of therapeutic intent will have consequences for the participant and, hence, will require some level of disclosure. The method of disclosure - written versus oral or face-to-face - will depend, in part, on the level of risk associated with the therapeutic research components. For example, a randomized trial of treatment for pediatric leukemia could entail significant investment by the child and family, including possible excess risk of life-threatening infections, admission to hospital and toxic effects to organs, and therefore warrant an offer of oral or face-to-face disclosure. In contrast, for a study comparing 2 antifungal medications for athlete's foot, the results may be offered in written format. 
Studies of nontherapeutic intention can be divided into those associated with minimal risk versus those involving more than minimal risk. Participants can be expected to have more interest in the outcome of studies with more than minimal risk. Thus, higher-risk studies will likely require more rigorous, direct disclosure of results compared with studies of less direct interest to the participants, such as those exploring basic science questions. An offer of written disclosure is sufficient for nontherapeutic studies with minimal risk and consequences, such as disclosure of survey results.

Although the link between method of disclosure and therapeutic or nontherapeutic risk has not been established, we are in the process of studying whether participants' desire for disclosure is based on such a connection.

We propose the use of a hierarchy of study types, whereby studies are divided according to their therapeutic versus nontherapeutic intent and on a continuum from relatively low risk of participation to high risk. As the risk to the study participant increases, disclosure will likely become more detailed and more time-consuming (incurring greater costs); for studies with little intrinsic risk, a brief statement to each participant will be sufficient.

\section{Consequences of disclosure}

The second assessment should estimate the potential consequences to the participant falling into the range of findings, from interventions that will reduce the risk of future harm to those that have no direct impact. An example of the former (a significant consequence) is the need for breast cancer screening in female survivors of adolescent Hodgkin's disease who have received radiotherapy..$^{18} \mathrm{An}$ example of the latter (no anticipated consequence) is the validation of a psychometric tool in normal volunteers.

The return of results itself can be associated with signifi- cant distress in participants, including anger, sadness and fear. ${ }^{19}$ If necessary, the assessment of expected consequences may be assisted by a lay panel (made up of former participants or peers).

We have argued that all human research participants should be accorded the respect of an offer of results. This would require not only a dramatic increase in researchers' investment of time, but may also require modifications in the study design to allow the generation of individual-level results. This would, in turn, have cost implications related to maintenance of privacy and confidentiality. We have previously argued that results for participants should be subject to the same rigor of interpretation that is required for peer-reviewed publication. ${ }^{7}$ As a result, we believe that only individual-level results with sufficient predictive value should be shared with participants.

Associated costs may, therefore, include costs of study and software design, the extra effort required to generate individual-level results, the increased complexity of maintaining confidentiality, the costs of the disclosure procedure itself and the possible need for counselling by health care professionals beyond oral disclosure.

\section{Logistics of follow-up}

The size and duration of the study may have an impact on the sophistication of the database used to compile the results and follow-up procedures, especially when results are not expected for many years.

We believe that participants should be engaged in the process and to some degree be accountable for maintaining a liaison with researchers for the express purpose of receiving results. ${ }^{7}$ Although a password-protected, researchrelated Web site may seem appealing to facilitate this, preliminary evidence suggests that participants do not favour

\begin{tabular}{|c|c|c|c|}
\hline $\begin{array}{l}\text { Mode of } \\
\text { dissemination }\end{array}$ & Time requirement & Items over and above basic requirements* & Relative cost $\dagger$ \\
\hline Written & Nonintensive & Mailing costs & Low \\
\hline Internet & Nonintensive & $\begin{array}{l}\text { Notification mailing costs } \\
\text { Web site creation and hosting charges }\end{array}$ & Low to moderate \\
\hline Oral (telephone) & Highly intensive & $\begin{array}{l}\text { Notification mailing costs } \\
\text { Personnel (telephone caller and supervisor) } \\
\text { Facilities (telephone equipment) }\end{array}$ & High \\
\hline Oral (group) & $\begin{array}{l}\text { Moderately } \\
\text { intensive }\end{array}$ & $\begin{array}{l}\text { Notification mailing costs } \\
\text { Personnel (group facilitator and supervisor) } \\
\text { Facilities (hall) }\end{array}$ & Moderate to high \\
\hline Oral (face-to-face) & Highly intensive & $\begin{array}{l}\text { Notification mailing costs } \\
\text { Personnel (researcher or designate) } \\
\text { Referrals as applicable } \\
\text { Facilities (clinic, laboratory) }\end{array}$ & High to very high \\
\hline
\end{tabular}




\section{Box 1: Elements to be considered in disclosure of research results to research participants}

- The nature and context of the study

- The original study question(s)

- The role of the participant in the study

- A summary of the main results and conclusions of the study

- Known implications for the participant - immediate and long-term

- Specific risks that have been identified for the participant with instructions for follow-up

- A written copy of the disclosure discussion in a lay format

- If applicable, referral to other professionals (i.e., medical specialists, psychologists or social workers)

- In the event of severe consequences, it may be appropriate for the researcher to assemble a team proactively to provide comprehensive support

this route. ${ }^{20}$ Lost-to-follow up rates could be improved by providing routine, high-quality information about the potential benefits of receiving research results, an estimate of when the results might be available and information about access to a summary of results.

\section{Summary}

Estimating the costs of dissemination will be relatively straightforward for many studies but will be more challenging when it is necessary to quantify the differences in cost due to intrinsic risk, consequences and time elements. Researchers and granting agencies should consider the offer to return results to research participants as a mandatory part of practice and adjust budgets and duration of funding accordingly. If the disclosure is expected to be associated with harm, and if that harm can be minimized through direct disclosure, then direct disclosure ought to be offered. It is essential to determine the wants and needs of participants with respect to how best to offer and disseminate research results, and we are currently exploring these questions.

This article has been peer reviewed.

From the Division of Pediatric Hematology and Oncology, Department of Pediatrics, IWK Health Centre (Fernandez), the Department of Medicine, Queen Elizabeth II Health Sciences Centre (Skedgel), and the Department of Bioethics (Weijer), Dalhousie University, Halifax, NS
Competing interests: None declared.

Contributors: Conrad Fernandez conceived and wrote the initial draft of the manuscript. Chris Skedgel and Charles Weijer contributed further valuable ideas. All of the authors were involved in writing the many draft modifications of this article and approved the version submitted to be published.

\section{References}

1. Fernandez CV, Kodish E, Shurin S, Weijer C. Offering to return results to research participants: attitudes and needs of principal investigators in the Children's Oncology Group. 7 Pediatr Hematol Oncol 2003;25(9):704-8.

2. Fernandez CV, Kodish E, Taweel S, Shurin S, Weijer C. Disclosure of the right of research participants to receive research results: an analysis of consent forms in the Children's Oncology Group. Cancer 2003;97(11):2904-9.

3. TriCouncil Policy Statement. Ethical conduct for research involving humans. Ottawa Medical Research Council of Canada, Natural Sciences and Engineering Research Council and Social Sciences and Humanities Research Council of Canada. Available: www.ncehr-cnerh.org/english/code_2 (accessed 2004 Mar 16).

4. Code of federal regulations. Title 45: public welfare. Part 46: Protection of buman subjects. Washington: Department of Health and Human Services, National Institutes of Health and Office for Protection from Research Risks. Available: http:/ohrp.osophs.dhhs.gov/humansubjects/guidance $45 \mathrm{cfr} 46 . \mathrm{htm}$ (accessed 2004 Mar 16).

5. Partridge AH, Burstein HJ, Gelman RS, Marcom PK, Winer EP. Do patients participating in clinical trials want to know study results? 7 Natl Cancer Inst 2003;95(6):491-2.

6. Partridge $\mathrm{AH}$, Winer EP. Informing clinical trial participants about study results. 7AMA 2002;288(3):363-5

7. Fernandez CV, Kodish E, Weijer C. Informing study participants of research results: an ethical imperative. IRB 2003;25(3):12-9.

8. Weijer C, Goldsand G, Emanuel EJ. Protecting communities in research current guidelines and limits of extrapolation. Nat Genet 1999;23(3):275-80.

9. Diller L, Medeiros Nancarrow C, Shaffer K, Matulonis U, Mauch P, Neuberg $\mathrm{D}$, et al. Breast cancer screening in women previously treated for Hodgkin's disease: a prospective cohort study. 7 Clin Oncol 2002;20(8):2085-91.

10. Boal WL, Friedland J, Schulte PA. Workers' response to risk notification. Am f Ind Med 1995;27(4):471-83.

11. Acquavella JF, Collins JJ. Perspective on the content of worker notifications. Am f Ind Med 1993;23(1):77-83

12. Juzych MS, Shin DH, Coffey JB, Parrow KA, Tsai CS, Briggs KS. Pattern of publication of ophthalmic abstracts in peer-reviewed journals. Opbthalmology 1991;98(4):553-6.

13. De Bellefeuille C, Morrison CA, Tannock IF. The fate of abstracts submitted to a cancer meeting: factors which influence presentation and subsequent publication. Ann Oncol 1992;3(3):187-91.

14. Dorval M, Patenaude AF, Schneider KA, Kieffer SA, DiGianni L, Kalkbrenner KJ, et al. Anticipated versus actual emotional reactions to disclosure of results of genetic tests for cancer susceptibility: findings from $\mathrm{p} 53$ and $B R C A 1$ testing programs. 7 Clin Oncol 2000;18(10):2135-42.

15. Codori AM, Brandt J. Psychological costs and benefits of predictive testing for Huntington's disease. Am 7 Med Genet 15 1994;54(3):174-84.

16. Hayden MR, Bloch M, Wiggins S. Psychological effects of predictive testing for Huntington's disease. Adv Neurol 1995;65:201-10.

17. Weijer C. The ethical analysis of risk. 7 Law Med Ethics 2000;28(4):344-61.

18. Bhatia S, Robison LL, Oberlin O, Greenberg M, Bunin G, Fossati-Bellani F, et al. Breast cancer and other second neoplasms after childhood Hodgkin's disease. N Engl 7 Med 1996;334(12):745-51.

19. Schulz CJ, Riddle MP, Valdimirsdottir HB, Abramson DH, Sklar CA. Impact on survivors of retinoblastoma when informed of study results on risk of second cancers. Med Pediatr Oncol 2003;41(1):36-43.

20. Fernandez CV, Taweel S, Kodish E, Weijer C. Disclosure of research results to research participants: focus group and questionnaire development examining attitudes of participants. Blood 2003;102(11):202a.

Correspondence to: Dr. Conrad V. Fernandez, IWK Health

Centre, Box 3070, 5850 University Ave., Halifax NS B3J 3G9;

fax902 470-7216; conrad.fernandez@iwk.nshealth.ca 